CASSOWARY volume 5 (1) Januari 2022: 81 - 86

ISSN : 2614-8900

E-ISSN : 2622-6545

Program Pascasarjana Universitas Papua, https://pasca.unipa.ac.id/

\title{
Peran serta masyarakat mereduksi sampah anorganik melalui Bank Sampah di Distrik Malaimsimsa Kota Sorong
}

\author{
Andreas Adiii ${ }^{1}$, Marlyn N. Lekitoo ${ }^{2)}$, Meike M. Lisangan ${ }^{3)^{*}}$ \\ ${ }^{1)}$ Program Studi S2 Ilmu Lingkungan, Program Pascasarjana, Universitas Papua, Jalan Gunung \\ Salju, Amban, Manokwari, Papua Barat, 98314, Indonesia \\ *Email: mml.talakua@gmail.com
}

Disubmit: 16 Maret 2021, direvisi: 13 Januari 2022, diterima: 26 Januari 2022

Doi: https://doi.org/10.30862/casssowary.cs.v5.i1.96

\begin{abstract}
The production of household waste increases every day in line with the increase in the number of products and the comsumption pattern of people. The things that must be done to overcome the increase in the amount of waste is by reducing the amount of waste from its source using waste. This study aims to determine the role of the community in the management of inorganic waste through the Waste Bank in the Malaimsimsa District and how much is the contribution of the Waste Bank in reducing the amount of inorganic waste in the Malaimsimsa District and the income that can be obtained through the Waste Bank. This study used a qualitative description method. The results of this study indicate that the existence of a Waste Bank in Malaimsimsa District can reduce waste production in the final dumpsite, but waste recycling and sorting have not been maximally carried out by the community and Waste Bank managers. The composition of the wastes in Malaimsimsa District consists of $39.90 \%$ inorganic waste that consist of $29.11 \%$ of plastics, $8.8 \%$ of papers, $0.17 \%$ of glasses/bottles, and $1.82 \%$ of iron/can.
\end{abstract}

Keywords: Community Role, Inorganic Waste, Reduction, Waste Bank

\section{PENDAHULUAN}

Sampah perkotaan merupakan salah satu masalah yang perlu mendapat perhatian yang serius. Pertambahan jumlah penduduk di perkotaan yang pesat berdampak terhadap peningkatan jumlah sampah yang dihasilkan (Abe, 2001). Kota Sorong merupakan pusat perekonomian, mempunyai permasalahan sampah yakni peningkatan jumlah sampah. Berdasarkan hasil survei yang dilakukan untuk melihat potensi persampahan di Kota Sorong, sampah yang dihasilkan penduduk/keluarga sama dengan 2,45 $\mathrm{kg}$ per kepala keluarga
$(\mathrm{KK}) /$ hari, dan setiap KK rata-rata ada 5 jiwa. Berdasarkan data ini maka terhitung setiap orang menghasilkan sampah 0,49 kg/hari (Badan Pusat Statistik Kota Sorong, 2013).

Peran serta masyarakat merupakan salah satu faktor penting untuk memecahkan permasalahan sampah diperkotaan (Departemen Pekerjaan Umum, 2006). Sampai saat ini peran serta masyarakat secara umum hanya sebatas pembuangan sampah saja belum sampai pada tahapan pengelolaan sampah yang dapat bermanfaat kembali bagi masyarakat (Mastur, 2003). 
Pengelolaan sampah dengan cara pemilahan sampah organik dan anorganik sudah di lakukan oleh beberapa Distrik di Kota Sorong, diantaranya adalah Distrik Malaimsimsa, Kota Sorong. Distrik Malaimsimsa, Kota Sorong adalah wilayah yang sudah memberdayakan masyarakat dalam pengelolaan sampah dengan membentuk Unit Bank Sampah. Namun belum diketahui sejauh mana peran serta masyarakat di wilayah tersebut dalam mereduksi jumlah sampah terutama sampah anorganik di kota Sorong. Oleh karena itu, dalam penelitian ini akan dikaji sejauh mana peran serta masyarakat tersebut.

Penelitian ini bertujuan untuk mengetahui peran serta masyarakat dalam mereduksi timbulan sampah anorganik melalui keaktifannya sebagai nasabah bank sampah.

\section{MATERI DAN METODE}

Metode yang digunakan dalam penelitian ini adalah metode deskriptif dengan teknik observasi/survey.

\section{Tempat dan Waktu Penelitian}

Penelitian ini dilaksanakan di Distrik Malaimsimsa, Kota Sorong pada bulan Oktober - Desember 2018.

\section{Bahan dan Alat Penelitian}

Bahan yang digunakan dalam penelitian ini adalah sampah pada bank sampah, sedangkan peralatan yang digunakan meliputi pena, kertas, buku tabungan, karung plastik, kantong plastik, tali rafia, gerobak, sarung tangan, kamera, pengait sampah, dan kalkulator.

\section{Sumber Data}

Data dalam penelitian ini dibatasi pada data primer dan data sekunder. Data primer berupa data Jumlah unit Bank Sam-pah, nasabah dan harga per-kg sedangkan data sekunder berupa luas
Distrik, jumlah penduduk, pendidikan, dan pekerjaan.

\section{Variabel Pengamatan}

Variabel yang akan diteliti dalam penelitian ini adalah:

a. Jumlah Bank sampah

b. Jumlah Nasabah tiap Bank Sampah

c. Jumlah nasabah aktif

d. Jumlah (berat) sampah yang disetor tiap nasabah ke Bank Sampah setiap minggu $(\mathrm{kg})$

e. Nilai / harga sampah per $\mathrm{kg}(\mathrm{Rp} / \mathrm{kg})$

\section{Analisis Data}

Data yang diperoleh disajikan dalam tabel dan foto, lalu dibahas secara deskriptif.

\section{HASIL DAN PEMBAHASAN}

Volume dan Nilai Ekonomis Timbulan Sampah Anorganik di Distrik Malaimsimsa

Volume sampah setiap kota selalu meningkat seiring dengan bertambahnya jumlah penduduk. Sampah tersebut berupa sampah organic (Riruma, et al, 2021) dan anorganik (Prajati, 2019). Sampah anorganik dikategorikan ke dalam beberapa jenis seperti kertas, kardus, kaca/gelas, plastik, besi dan logam lainnya (SNI, 2008). Data jumlah dan jenis sampah yang di peroleh dari Distrik Malaimsimsa terdiri dari sampah kaleng, kertas, plastik, besi dan aki/alumunium. Volume dan nilai ekonomis timbulan sampah anorganik di Distrik Malaimsimsa ditampilkan pada Tabel 1. Data tersebut menunjukkan bahwa persentase sampah kertas di Distrik Malaimsimsa lebih banyak, karena di Distrik Malaimsimsa terdapat beberapa Supermarket, ruko, toko dan sekolah sebagai sumber produksi sampah karton dan kertas. Namun sampah kertas ini juga yang lebih banyak tereduksi di bank 
sampah dibanding dengan sampah jenis lainnya, sedangkan untuk sampah Accu dan Alumunium sangat sedikit, karena nasabah langsung menjual ke pengepul dengan harga yang lebih mahal.

\section{Jumlah Sampah Tereduksi di Distrik Malaimsimsa}

Jumlah sampah tereduksi di Distrik Malaimsimsa dapat dilihat pada Tabel 2. Data ini menunjukkan bahwa setiap tahun terjadi peningkatan timbulan sampah yang dikumpulkan di bank sampah serta meningkatnya pendapatan bagi para nasabah bank sampah (Basriyanta, 2007). Peningkatan timbulan sam-pah di bank sampah dapat menjadi indi-kator jumlah sampah yang tereduksi dari lingkungan. Secara keseluruhan jumlah sampah yang tereduksi dari tahun 2016 sampai dengan tahun 2018 adalah di bawah $1 \%$.

\section{Nasabah Aktif di Unit Bank Sampah Distrik Malaimsimsa \\ Dari hasil penelitian pada 4 unit} di Distrik Malaimsimsa, tidak semua nasabah aktif mengumpulkan sampahnya pada bank sampah (Tabel 3). Terdapat 2 unit Bank Sampah Sekolah yaitu Yayasan Al-Izzah dan MTs Muhammadiyah I, namun tidak seluruh siswa aktif dalam mengumpulkan sampahnya. Hal yang sama juga terjadi pada 2 Unit Bank Sampah yang terdapat di Kelurahan Klabulu dan Kelurahan Malaingkedi. Hanya beberapa nasabah yang aktif mengumpulkan sampahnya di Unit Bank Sampah setiap minggu. Partisipasi aktif nasabah menjadi salah satu faktor berkembangnya sebuah unit bank sampah (Triana dan Sembiring, 2019). Kurangnya partisipasi nasabah juga berpengaruh pada jumlah sampah yang berhasil direduksi.

Tabel 1. Volume dan nilai ekonomis potensi pemanfaatan komponen sampah di Distrik Malaimsimsa

\begin{tabular}{clrrr}
\hline No & Jenis Sampah & Persentase $(\%)$ & Berat $(\mathrm{kg})$ & Nilai Uang (Rp) \\
\hline 1 & Kaleng & 15,9 & $2.524,3$ & 37.094 .134 \\
2 & Kertas & 50,9 & $8.087,4$ & 4.884 .596 \\
3 & Plastik & 25,6 & $4.073,3$ & 8.069 .265 \\
4 & Besi & 6,1 & 976,1 & 338.550 \\
5 & Aki/aluminium & 1,5 & 240,7 & 939.025 \\
\hline Total & & 100 & $15.901,8$ & 51.325 .570 \\
\hline
\end{tabular}

Tabel 2. Jumlah sampah yang tereduksi dari tahun 2016 - 2018 pada bank sampah di Distrik Malaimsimsa

\begin{tabular}{lcrrrr}
\hline No & Tahun & Jumlah Sampah $(\mathrm{kg})$ & Reduksi $(\mathrm{Kg} / \mathrm{Thn})$ & Persentase $(\%)$ & Harga $(\mathrm{Rp})$ \\
\hline 1. & 2016 & $6.670 .389,60$ & 15.430 & 0,23 & 33.435 .950 \\
2. & 2017 & $6.752 .481,75$ & $17.133,5$ & 0,25 & 36.146 .500 \\
3. 2018 & $6.852 .637,75$ & $15.901,8$ & 0,23 & 51.325 .570 \\
\hline \multicolumn{2}{l}{ Total } & $20.275 .509,51$ & $48.465,3$ & 0,71 & - \\
\hline \multicolumn{2}{l}{ Rata - rata } & $6.758 .503,03$ & $16.155,1$ & 0,24 & - \\
\hline
\end{tabular}

Tabel 3. Nasabah Aktif Pada Unit Bank Sampah

\begin{tabular}{llcc}
\hline No & Unit Bank Sampah & Jumlah Nasabah (Orang) & Nasabah Aktif (orang) \\
\hline 1 & Malaingkedi & 482 & 60 \\
2 & Klabulu & 239 & 40 \\
3 & MTS Muhamadiah & 100 & 22 \\
4 & Yayasan Al Izzah & 210 & 40 \\
\hline & Total & 1031 & 162 \\
\hline
\end{tabular}


Berdasarkan data pada Tabel 3 dapat dilihat bahwa nasabah yang aktif tertinggi pada bank sampah Malaingkedi sebanyak 60 orang dan terendah pada bank sampah MTs Muhamadiyah 22 orang. Hal ini diduga karena jumlah nasabah pada bank sampah Malaingkedi memiliki nasa-bah tertinggi sehingga berpengaruh terha-dap jumlah nasabah aktif. Namun yang menarik untuk dikaji lebih mendalam yaitu pada bank sampah Klabulu dan Yayasan Al-Izzah yang keduanya memiliki jumlah nasabah aktif 40 orang. Bila dilihat dari jumlah nasabah, bank sampah Klabulu memiliki jumlah nasabah yang lebih banyak (482 orang) dari pada Al-Izzah (210 orang), namun memiliki jumlah nasabah aktif yang sama (40 orang). Hal ini menunjukkan bahwa siswa lebih mudah diarahkan oleh dewan guru jika dibandingkan masyarakat umum.

\section{Partisipasi Masyarakat Mengelola Sampah}

Partisipasi masyarakat untuk mengelola sampah melalui Bank Sampah di Distrik Malaimsimsa ditampilkan pada Tabel 4. Berdasarkan data pada table tersebut, jumlah penduduk meningkat sedangkan pertambahan jumlah nasabah justru menurun. Sehingga dapat dikatakan bahwa partisi-pasi masyarakat cenderung menurun. Hal ini sejalan dengan pendapat Hadi (2005) dari segi kualitas pertisipasi atau peran serta masyarakat sangat penting untuk mendukung keberhasilan dalam upaya pengelolaan sampah.

Data pada Tabel 4 menunjuk-kan bahwa meskipun pada kurun waktu 2016-2017 persentase nasabah aktif mengalami penurunan, namun pada tahun 2017-2018 cenderung menga-lami peningkatan. Hal ini diduga karena adanya sosialisasi dan kampanye pada masyarakat serta adanya imbalan jasa melalui Bank Sampah kepada para
Nasabah. Meningkatnya peran serta masyarakat dan merubah prilaku masyarakat dalam pengelolaan sampah dapats mengurangi volume sampah di TPS serta membantu Pemerintah mengurangi biaya pengangkutan ke TPA, memperpanjang usia TPA dan meminimalisir TPS (Armando, 2008). Manfaat lainnya dari peningkatan nasabah aktif adalah meningkatkan pengetahuan masyarakat dalam pengelolaan sampah dan kebersihan lingkungan (Syafrudin, 2004) serta edukasi bagi siswa siswi di Distrik Malaimsimsa.

Peran serta masyarakat Distrik Malaisimsa menjadi faktor keberhasilan didalam menata dan meminimalisir TPS sehingga membantu pemerintah dalam hal mengurangi biaya pengangkutan sampah ke TPA, memperpanjang usia TPA. Hal ini senada dengan hasil penelitian yang dilakukan oleh Wahyuni et al (2014) yang menunjukkan bahwa peran serta masyarakat Kabupaten Magetan dalam mengelola sampah dengan sistem 3R dapat memperpanjang umur TPA Milangsari Kabupaten Magetan.

\section{Jumlah Sampah yang Direduksi}

Seiring perkembangan pembangunan, meningkatnya usaha ekono-mi maupun pertumbuhan penduduk maka meningkat pula sampah anorga-nik oleh karena itu perlunya kerjasama semua elemen masyarakat. Jumlah sampah yang tereduksi selama kurun waktu 2016-2018 dapat dilihat pada Tabel 5. 
Tabel 4. Jumlah Penduduk dan Jumlah Nasabah Bank Sampah di Distrik Malaimsimsa

\begin{tabular}{ccccccc}
\hline Tahun & $\begin{array}{c}\text { Jmlah } \\
\text { Penduduk }\end{array}$ & $\begin{array}{c}\text { Pertambahan } \\
\text { Jumlah } \\
\text { Penduduk }\end{array}$ & $\begin{array}{c}\text { Jmlah } \\
\text { Nasabah }\end{array}$ & $\begin{array}{c}\text { Persentase } \\
\text { Partisipasi } \\
(\%)\end{array}$ & $\begin{array}{c}\text { Jumlah } \\
\text { Nasabah } \\
\text { Aktif (orang) }\end{array}$ & $\begin{array}{c}\text { Persentase } \\
(\%)\end{array}$ \\
\hline $\mathbf{2 0 1 6}$ & 37.296 & - & 563 & 1,5 & 119 & 21,13 \\
$\mathbf{2 0 1 7}$ & 37.755 & 459 & 978 & 2,6 & 137 & 14 \\
$\mathbf{2 0 1 8}$ & 38.315 & 560 & 1031 & 2,7 & 163 & 16 \\
\hline
\end{tabular}

Tabel 5. Timbulan Sampah Tereduksi

\begin{tabular}{lcccccc}
\hline Tahun & $\begin{array}{c}\text { Jumlah } \\
\text { Timbulan } \\
(\text { Kg/tahun) }\end{array}$ & $\begin{array}{c}\text { Jumlah yang } \\
\text { direduksi } \\
(\mathbf{k g})\end{array}$ & $\begin{array}{c}\text { Persentase } \\
(\boldsymbol{\%})\end{array}$ & $\begin{array}{c}\text { Selisih } \\
(\boldsymbol{\%})\end{array}$ & $\begin{array}{c}\text { Jumlah } \\
(\mathbf{R p}) / \text { tahun }\end{array}$ & $\begin{array}{c}\text { Rata-rata } \\
(\mathbf{R p}) / \text { Bulan }\end{array}$ \\
\hline $\mathbf{2 0 1 6}$ & 6.670 .389 .60 & 15.430 & 0,23 & - & 33.435 .950 & 2.786 .329 \\
$\mathbf{2 0 1 7}$ & 6.752 .481 .75 & 17.133 .5 & 0.25 & 0.02 & 36.146 .500 & 3.012 .208 \\
$\mathbf{2 0 1 8}$ & 6.852 .637 .75 & $15.901,8$ & 0.29 & 0.04 & 51.325 .570 & 4.334 .644 \\
\hline
\end{tabular}

Tabel 5 menunjukkan bahwa jumlah sampah yang dihasilkan oleh masyarakat distrik Malaimsimsa setiap tahun meningkat, namun sampah yang tereduksi juga mengalami peningkatan walaupun persentasinya tidak mencapai $1 \%$. Peningkatan ini memperlihatkan bahwa masyarakat mulai sadar akan pentingnya bank sampah. Data ini mengandung arti bahwa masyarakat mulai berperan serta dalam mereduksi sampah anorganik. Kesadaran ini dianggap juga sebagai imbas masyarakat mulai merasakan dampak ekonomis dari bank sampah. Hal ini sejalan dengan hasil penelitian yang dilakukan oleh Sutiawati et. al (2021) yang melihat dampak ekonomi dari program bank sampah bagi masyarakat di Kota Makassar.

Berdasarkan Tabel 5 terlihat bahwa tahun 2016-2018 terjadi peningkatan pendapatan bagi masyarakat Distrik Malaimsimsa yaitu sebesar $\mathrm{Rp}$ 225.879 (2016-2017) dan di tahun 2018 meningkat sebesar Rp. 1.322.436. Hal ini dapat terjadi karena peningkatan nasabah aktif sehingga mempengaruhi pendapatan.

\section{KESIMPULAN}

Peran serta masyarakat dalam pengelolaan sampah melalui bank sampah saat ini sudah cukup baik. Keberhasilan peran serta masyarakat dalam mengelola sampah secara komprehensif tahun 2018 dapat dilihat dari jumlah Nasabah sebanyak 1.031 orang, sampah tereduksi sebanyak 15.901,8 Kg/thn dan pendapatan masyarakat atau nasabah sebesar Rp. 51.325.570,00.

\section{DAFTAR PUSTAKA}

Abe, A. (2001). Perencanaan Daerah Memperkuat Prakarsa Rakyat Dalam Otonomi Daerah. Lapera Pustaka Utama, Yogyakarta.

Armando, R. (2008). Penanganan dan Pengelolaan Sampah. Penebar Swadaya, Jakarta.

Badan Pusat Statistik Kota Sorong. (2013). Kota Sorong Dalam Angka 2012. BPS Kota Sorong. Kota Sorong.

Basriyanta. (2007). Memanen Sampah, Kanisius, Yogyakata.

Departemen Pekerjaan Umum, (2006). Kebijakan dan Strategi Nasional Pengelolaan Persampahan di Indonesia. Departemen Pekerjaan Umum, Jakarta. 
Hadi, S.P. (2005). Dimensi Lingkungan Perencanaan Pembangunan, Gadjah Mada University Press, Yogyakarta.

Mastur, M. (2003). Partisipasi Masyarakar Dalam Proses Pengambilan Keputusan Pembangunan Fisik Kelurahan Pisang Candi Kecamatan Sukun Malang. Jurnal Penelitian Universitas Merdeka Malang $\mathrm{XV}(2)$ : 632-642.

Menteri Lingkungan Hidup. (2012). Peraturan Menteri Negara Lingkungan Hidup Republik Indonesia Nomor 13 tahun 2012

Prajati, G. dan Persunay, A.J. (2019). Analisis Faktor Sosiodemografi dan Sosioekonomi Terhadap. Jurnal Rekayasa Sipil dan Lingkungan. 3(1): 8-16.

Republik Indonesia. (2008). UndangUndang Nomor 18 tahun 2008 tentang Pengelolaan Sampah.

Riruma, N., Sinaga, N., \& Lekitoo, M. N. (2021). Kajian pengelolaan sampah rumah tangga (SRT) dan sampah sejenis sampah rumah tangga (SSRT)) di Kabupaten Teluk Bintuni. Cassowary, 4(1), 39-51.

https://doi.org/10.30862/casssowa ry.cs.v5.i1.67

Standart Nasional Indonesia. (2008) Nomor SNI-03-3242-2008 tentang Tata Cara Pengelolaan Sampah di Permukiman, Badan Standar Nasional (BSN).

Sunarti N.M. (2003). Upaya Pengelolaan Sampah Rumah Tangga Untuk Mewujudkan Kebersihan Lingkungan di Kota Denpasar. Jurnal Ilmu Lingkungan. 2(1):1-10

Sutiawati, D.A., Abdullah, M.T., Yani, A.A. (2021). Analisis Dampak Program Bank Sampah Bagi Masyarakat Urban: Studi Kasus Di Kota Makassar. Development
Policy and Management Review. 1(1):18-31

Syafrudin. (2004). Pengelolaan Sampah Berbasis Masyarakat. Prosiding Diskusi Interaktif Pengelolaan Sampah Terpadu, Program Magister Ilmu Lingkungan Universitas Diponegoro, Semarang.

Triana, A.P., Sembiring, E. (2019). Evaluasi Kinerja Dan Keberlanjutan Program Bank Sampah Sebagai Salah Satu Pendekatan Dalam Pengelolaan Sampah Dengan Konsep 3R. Jurnal Teknik Lingkungan. 25(1):15-28

Wahyuni, E.T., Sunarto, Setyono, P. (2014). Optimalisasi Pengelolaan Sampah Melalui Partisipasi Masyarakat dan Kajian Extended Producer Responsibility (EPR) di Kabupaten Magetan. Jurnal Ekosains. VI(1):8-23 